\title{
EFEITO DE ANTOCIANINA E PRÓPOLIS EM DIABETES INDUZIDA EM COELHOS
}

\author{
EFFECTS OF ANTHOCYANIN AND PROPOLIS IN DIABETIC RABBITS
}

Tânia Toledo de Oliveira1, Tanus Jorge Nagem², Aloísio da Silva Pinto ${ }^{3}$, Dejair Message ${ }^{4}$, Adelson Luiz Araújo Tinoco $^{5}$, Neuza Maria Magalhães ${ }^{1}$, José Francisco da Silva ${ }^{6}$, Alfredo Alcides Goicochea Huertas ${ }^{4}$, José Geraldo Pinto ${ }^{7}$ Graciela Bergamaschi Pezerico ${ }^{8} \&$ Alexandre Couto Tsiomis ${ }^{8}$

\begin{abstract}
${ }^{1}$ Docente. Departamento de Bioquímica e Biologia Molecular - UFV, ${ }^{2}$ Docente. Departamento de Química - UFOP - MG; ${ }^{3}$ Docente Departamento de Veterinária - UFV; ${ }^{4}$ Docente Departamento de Biologia Animal - UFV; ${ }^{5}$ Docente do Departamento de Nutrição - UFV $; 6$ Técnico. Departamento de Zootecnia - UFV; ${ }^{7}-$ Técnico. Departamento de Bioquímica e Biologia Molecular - UFV, ${ }^{8}$ Graduando. Departamento de Veterinária - UFV.

CorRespondência: Profa. Dra. Tânia Toledo de Oliveira-Av: Ph Rolphs s/n. CEP 36571-000, Viçosa - MG, Brasil; email-ttoledo@mail.ufv.br; fax -0313138991429
\end{abstract}

OLIVEIRA TT; NAGEM TJ; PINTO AS; MESSAGE D; TINOCO ALA; MAGALHÃES NM; SILVA JF; HUERTAS AAG; PINTO JG; PEZERICO GB \& TSIOMIS AC. Efeito de antocianina e própolis em diabetes induzida em coelhos. Medicina, Ribeirão Preto, 35: 464-469, out./dez. 2002.

RESUMO: A síndrome clínica da diabetes é caracterizada pela redução da capacidade de metabolização de carboidratos e gorduras, resultando em aumento dos níveis séricos de glicose (hiperglicemia) e lipídios (hiperlipidemia), acarretando em degeneração vascular prematura. $\mathrm{O}$ objetivo do presente trabalho foi testar os efeitos da antocianina e do própolis ministrados nas doses de $20 \mathrm{mg}$ e $150 \mathrm{mg}$, respectivamente, em coelhos diabéticos para a verificação dos efeitos sobre os níveis de glicose e triacilglicerol. Os grupos experimentais de coelhos estudados foram: Grupo 1- grupo controle que somente recebeu ração; Grupo 2- grupo diabético que recebeu ração mais aloxano; Grupo 3- grupo diabético que recebeu ração, aloxano e 1 cápsula de antocianina (20mg) diariamente; Grupo 4- grupo diabético que recebeu ração, aloxano e 1 cápsula de própolis (150mg) diariamente. Os Grupos 3 e 4 foram submetidos a vinte e oito dias de tratamento, com dosagem semanal dos níveis sanguíneos de glicose e de triacilglicerol. De acordo com os resultados obtidos, pode-se observar que, durante todo o período experimental, a antocianina foi mais eficaz, em induzir a queda dos níveis de glicose, com reduções de $10,78 \%$ aos 7 dias, $10,54 \%$ aos 14 dias, $17,33 \%$ aos 21 dias e 28,09\% aos 28 dias. Já o própolis apresentou redução de $22,69 \%$ aos 28 dias. Observou-se redução dos percentuais de variação de triacilgliceróis em $22,74 \%$ pela antocianina e $22,60 \%$ pelo tratamento com própolis aos 28 dias. Ao se compararem os Grupos 3 e 4 com o Grupo 2 (aloxano) durante todo o período experimental, os níveis de triacilgliceróis aumentaram no período de 0 a 21 dias.

UNITERMOS: Própolis. Diabetes. Antocianinas. Triacilgliceróis.

\section{INTRODUÇÃO}

A síndrome clínica da diabetes é caracterizada por distúrbios contínuos do metabolismo de carboidratos, lipídios e proteínas e várias alterações tissulares, provocadas pela deficiência de atividade insulínica, sendo caracterizada por hiperglicemia e glicosúria, apresentando um quadro clínico de poliúria, polidipsia, polifagia, e emagrecimento ${ }^{(1)}$.

Milhares de pacientes com diabetes padecem de complicações micro e macrovasculares. As complicações microvasculares tendem a predominar na

Agências financiadoras: FAPEMIG E CNPq 
diabetes do tipo 2, com a qual ocorrem lesões da microvasculatura, e podem levar a amputações não traumáticas dos membros inferiores ${ }^{(2)}$. A nefropatia diabética é a causa principal de enfermidade renal em estado terminal, e com ela se desenvolve uma falha renal crônica, que se agrava com o tempo. Entre os diabéticos há duas vezes mais probabilidade de acidente vascular cerebral e de enfermidade coronária cardíaca, do que na população em geral $^{(2)}$.

$\mathrm{Na}$ ausência de insulina ou eficácia de sua atividade, tem se a atividade da lípase reduzida e, portanto, a lipólise é diminuida e as concentrações dos lipídios triacilgliceróis, colesterol, e fosfolipídios aumentam no sangue ${ }^{(3)}$.

Na busca de novos medicamentos de ação hipoglicêmica, vários pesquisadores têm induzido a diabetes em cobaias e em outros animais, até em animais transgênicos, com maior freqüência em ratos, com a administração de aloxano e/ou estreptozocina ${ }^{(4)}$.

Morrison, $1987^{(5)}$ realizou estudos com extratos de Bixa orellana, aplicados em cães diabéticos, verificando efeitos hipoglicêmicos e tóxicos no fígado e pâncreas. Já Babu \& Srinivasan, 1995(4) investigaram a influência do colesterol e do corante natural curcumina na dieta de ratos com diabetes, induzida por estreptozocina. Nesse estudo, observou-se que os animais que receberam curcumina apresentaram melhor metabolismo de glicose, comparando-se com animais diabéticos do grupo que somente recebeu ração e do grupo que recebeu dieta com colesterol.

O própolis, possui uma série de substâncias resinosas, gomosas e balsâmicas. Tem consistência viscosa e é produzido pelas abelhas a partir de certas partes dos vegetais, como brotos e cascas de árvores. Como características químicas possui: álcoois, ácidos graxos, alcanos e alquenos. Além disso, possui mais de 150 compostos fenólicos, incluindo flavonóides (crisina, apigenina, galangina, quercetina e ácidos salicílico, ferúlico, cafeínico e gálico) e derivados do ácido cinâmico têm sido separados, no própolis, por cromatografia gasosa de microsseparação ${ }^{(6)}$. Muitas atividades biológicas foram verificadas para o própolis, dentre elas, a captura de células tumorais ${ }^{(7)}$, ação antioxidante $^{(8)}$, efeito anti-inflamatório ${ }^{(9)}$, atividade antibiótica ${ }^{(6)}$, ação antiviral ${ }^{(5)} \mathrm{e}$ atividade antiprotozoário ${ }^{(10,11)}$

Em muitos experimentos, em que a estreptozotocina é usada para induzir a diabetes, há quebra no DNA nuclear. Há estímulo da ADP polirribosessintetase ${ }^{(12 / 15)}$ que causa depleção nos níveis de $\mathrm{NAD}^{(16 / 19)}$. Em conseqüência, tem-se a redução acentuada da respiração celular, da produção de ATP, da síntese protéica, levando à morte celular ${ }^{(20)}$. Tem sido verificado que, com a administração de estreptozotocina, ocorre a diabetes, havendo a produção de NO e radicais de $\mathrm{CH}_{3} \mathrm{O}$ NO é uma molécula efetora e media a $1 \mathrm{~L}-1-\beta$-interleucina, que media a disfunção e a destruição de células beta. Tem sido verificado que o própolis é forte inibidor da $1 \mathrm{~L}-1-\beta$-interleucina e da NO sintase ${ }^{(21)}$.

As antocianinas compreendem um grupo de pigmentos de plantas do tipo flavonóide. Essas substâncias são encontradas nos vacúolos das plantas e suas cores dependem do $\mathrm{pH}$, de substituições no anel $\mathrm{B}$ e de suas copigmentações com outros flavonóides e ácidos fenólicos ${ }^{(22)}$. A estrutura básica das antocianinas é o cátion flavilium, a partir do qual se tem as 6 antocianidinas mais comuns: pelargonidina, cianidina, peonidina, delfinidina, petunidina e malvidina ${ }^{(23,24)}$. As antocianinas são glicosídeos que possuem açúcar na posição 3 do anel intermediário e participam do processo de formação de prostaglandina- endoperóxidos, como prostaciclinas instáveis, que inibem a agregação de plaquetas no processo de prevenção do estágio inicial da trombose. Esses processos podem ocorrer tanto em diabéticos quanto em indivíduos hipercolesterolêmicos e vários estudos têm indicado que flavonóides, como as antocianinas, atuam na prevenção da trombose $\mathrm{e}^{(25)}$.

Com base no exposto, o objetivo do presente trabalho foi avaliar os efeitos de antocianina incorporada em cápsulas na dose de $20 \mathrm{mg}$, e de própolis incorporado em cápsulas, na dose de $150 \mathrm{mg}$, administrados em coelhos com diabetes induzida por aloxano, para verificar os seus possíveis efeitos hipoglicemiantes e hipotrigliceridemiantes.

\section{MATERIAL E MÉTODOS}

Foram utilizados coelhos machos, albinos, da raça Nova Zelândia, com aproximadamente 2 meses de idade, pesando em média 1,5 a 2,0kg. Os animais foram alojados em gaiolas individuais, mantidos em temperatura ambiente, e receberam água à vontade $\mathrm{e}$ $120 \mathrm{~g}$ de ração comercial por dia (ração Socil, peletizada, para coelhos em reprodução e crescimento). Os 5 primeiros dias foram reservados para a adaptação dos animais ao novo local do experimento. Após esse período, 32 coelhos foram anestesiados com Xilazina $(5 \mathrm{mg} / \mathrm{kg} \mathrm{PV})$ e Cetamina $(20 \mathrm{mg} / \mathrm{kg} \mathrm{PV})$, para posterior administração de aloxano diluído em solução contendo $\mathrm{NaCl} 0,9 \%$, na dose de $100 \mathrm{mg} / \mathrm{kg} \mathrm{PV}$, via endovenosa na veia marginal da orelha. A fim de se evitar a morte dos animais por hipoglicemia, após a administração de aloxano, os coelhos receberam 3 
doses de $10 \mathrm{~mL}$ de glicose $50 \% \mathrm{p} / \mathrm{v}$, via intraperitonial, em intervalos de 4 horas. Foram coletadas, de todos os animais, amostras de sangue através do plexo venoso retroorbital, após 5 dias da aplicação do aloxano, e, em seguida, foi feita a quantificação dos níveis séricos de glicose e triacilgliceróis. Para tais dosagens, foram utilizados kits da marca Biolab e, para as quantificações, o aparelho multiparamétrico de dosagens bioquímicas (Alizé), com cadência de 150 testes/hora. Dos 32 coelhos tratados anteriormente, 8 não receberam doses de aloxano e constituíram o grupocontrole. Já os animais, cuja diabetes foi induzida, foram distribuídos em 3 grupos. Os animais do grupo controle foram anestesiados, e submetidos à aplicação de solução salina para equiparação com todos os outros grupos, incluindo a aplicação de glicose, via intraperitoneal. Em cada grupo, foram separados 8 animais. Os tratamentos tiveram continuidade conforme a seguinte descrição: GRUPO 1- [Controle]; GRUPO 2- [diabéticos tratados com aloxano]; GRUPO 3 -[diabéticos tratados com aloxano + uma cápsula de antocianina (na dose de 20mg) diariamente]; GRUPO 4 -[diabéticos tratados com aloxano + uma cápsula de própolis (na dose de $150 \mathrm{mg}$ ) diariamente]. A cada 7 dias, foram retiradas amostras de sangue, dosando-se glicose e triacilgliceróis, empregando-se o mesmo aparelho multiparamétrico de dosagens bioquímicas durante um período experimental de 28 dias. Para interpretação dos resultados, foi utilizado o teste Tukey e compararam-se os valores médios do Grupo 2, que recebeu ração + aloxano, com o Grupo 1 (Controle). Também foram realizados os testes em que se comparou o Grupo 3, que recebeu ração + aloxano + antocianina, com o Grupo 4, que recebeu ração + aloxano + própolis. O própolis foi fornecido pela indústria apícola e a antocianina pela empresa Christian Hansen. As cápsulas foram preparadas, usando-se talco como veículo.

\section{RESULTADOS E DISCUSSÃO}

De acordo com os resultados mostrados na Tabela I, pôde-se verificar que, durante todo o período experimental, os níveis de glicose foram maiores nos animais diabéticos do Grupo 2. Os animais do Grupo 3 tiveram os níveis de glicose reduzidos de 452,70 para 238,57 aos 28 dias. Já, no Grupo 4, os animais tiveram os níveis de glicose reduzidos de 459,83 para 256,50. Observou-se, também, que, durante o período experimental, o tratamento com antocianina (Grupo 3) teve uma melhor resposta na redução dos níveis de glicose.

É importante lembrar que o coelho está adaptado para utilizar rações com alta composição de proteínas e carboidratos, facilmente fermentáveis, das forragens, excretando as fibras não digeridas. Os carboidratos são absorvidos na forma de açúcares simples (glicose, galactose e frutose), obtidos da degradação de carboidratos complexos (amido, fibra). Dentre as principais enzimas que estão ligadas ao metabolismo de carboidratos podem-se destacar a amilase, a sacarase e a lactase, que digerem, respectivamente, o amido, a sacarose e a lactose em açúcares simples ${ }^{(26)}$.

Considerando que um indivíduo diabético tem as concentrações de glicose em torno de 70 a $110 \mathrm{mg} /$ $\mathrm{dL}$, em valores normais, e que valores acima de 126 $\mathrm{mg} / \mathrm{dL}$ são considerados diabéticos ${ }^{(27)}$, a variação tem

Tabela I: Concentração média de glicose $(\mathrm{mg} / \mathrm{dL}) \pm$ erro padrão em soro sanguíneo de coelhos diabéticos, submetidos a tratamento com antocianina e própolis.

\begin{tabular}{|c|c|c|c|c|c|}
\hline \multirow{2}{*}{ Grupos } & \multicolumn{5}{|c|}{ Dias de Tratamento } \\
\hline & 0 & 7 & 14 & 21 & 28 \\
\hline 1 & $128,52 \pm 2,20 B$ & $125,42 \pm 3,23 \mathrm{~B}$ & $127,63 \pm 3,10 \mathrm{~B}$ & $132,43 \pm 2,30 \mathrm{~B}$ & $113,07 \pm 2,145 \mathrm{~B}$ \\
\hline 2 & $315,20 \pm 1,50 \mathrm{~A}$ & $358,10 \pm 2,50 \mathrm{~A}$ & $289,38 \pm 2,20 \mathrm{~A}$ & $294,03 \pm 2,20 \mathrm{~A}$ & $331,78 \pm 2,10 \mathrm{~A}$ \\
\hline 3 & $452,70 \pm 2,30 \mathrm{aA}$ & $319,48 \pm 4,20 \mathrm{Ab}$ & $258,88 \pm 2,25 \mathrm{aC}$ & $243,07 \pm 3,12 \mathrm{aC}$ & $238,57 \pm 3,13 \mathrm{aC}$ \\
\hline 4 & $459,83 \pm 2,40 \mathrm{aA}$ & $354,29 \pm 2,30 \mathrm{aB}$ & $286,20 \pm 2,10 \mathrm{aC}$ & $292,10 \pm 4,10 \mathrm{aC}$ & $256,50 \pm 4,15 \mathrm{aD}$ \\
\hline
\end{tabular}


um alto efeito farmacológico. Observando-se que o efeito ocorreu durante 28 dias e considerando-se o longo período de terapia medicamentosa, necessário aos pacientes diabéticos, esse efeito pode ser muito mais pronunciado.

Para o tratamento com própolis, o experimento iniciado com grupos que tiveram concentrações de glicose variadas nos animais diabéticos, verificou-se que a redução de glicose foi mais acentuada aos 28 dias e apresentou uma variação de $22,69 \%$. Já para a antocianina do Grupo 3, notou-se que a redução ocorreu ao longo de todo o período, diminuindo os teores de glicose a partir dos 7 dias. Sendo o própolis constituído de flavonóides e ácidos fenólicos, possivelmente, a ação benéfica pode estar associada ao sinergismo dessas substâncias. A antocianina pertence à classe dos flavonóides. Um dos mecanismos de ação dos flavonóides mostra que eles se ligam a receptores de insulina ${ }^{(28)}$. A insulina, um hormônio com papel central na regulação da glicemia, atua de maneira coordenada no metabolismo lipídico e protéico. Age nas celulas através de seu receptor transmembranas que tem uma atividade tirosinaquinase. Em culturas de células animais, a ativação do receptor de insulina leva a uma subseqüente fosforilação dos resíduos de tirosina de uma proteína citoplasmática. A atividade tirosinaquinase é fundamental para os efeitos biológicos finais da insulina. As flavanonas têm capacidade de aumentar a atividade dessas enzimas ${ }^{(29)}$. Os resultados sugerem que os flavonóides (genisteína e quercetina) potencializam a atividade de tirosinaquinase dos receptores de insulina ${ }^{(29)}$.

A Tabela II mostra que os níveis de triacilgliceróis foram maiores para o Grupo 2 (tratado com aloxano), quando comparados aos do Grupo 1 . A glicose em excesso também é usada para síntese de triacilglicerol. A insulina promove a síntese de ácidos graxos no fígado, o estímulo da atividade da lípase lipoprotéica, o aumento subsequiente da captação de triacilgliceróis pelo tecido adiposo, com conseqüente armazenamento de gordura $^{(3)}$. Portanto, esses processos de hidrólise dos triacilgliceróis e captação de ácido graxo pelo tecido adiposo foram comprometidos nos animais tratados com aloxano, o que também justifica o aumento dos triacilgliceróis no Grupo 2. A Tabela II mostra, ainda, na comparação entre os Grupos 3 e 4 ao longo do período, que os animais tratados com antocianina mostraram reduções no nível de triacilgliceróis de $564,83 \mathrm{mg} / \mathrm{dL}$ para $87,84 \mathrm{mg} / \mathrm{dL}$ ( $84 \%$ de redução), e o grupo de coelhos diabéticos, tratado com própolis, teve as concentrações de triacilgliceróis de $721,08 \mathrm{mg} / \mathrm{dL}$ diminuídas para $88,00 \mathrm{mg} / \mathrm{dL}$ ( $88 \%$ de redução). Ape- nas aos 28 dias os dois tratamentos foram eficazes na redução dos níveis de triacilgliceróis. Devido ao fato de o própolis e as antocianinas conterem flavonóides, outros mecanismos de ação podem estar associados com a redução no final do experimento dos níveis de triacilgliceróis. Gomes, $1998^{(30)}$ utilizando ratos hiperlipidêmicos e não diabéticos, mostrou que compostos flavonoídes podem aumentar a atividade da lipase lipoprotéica, in vitro e in vivo, esta enzima é responsável pela hidrólise dos triacilgliceróis e está sendo este um dos mecanismos de ação para explicar as reduções. Este trabalho também cita o efeito de flavonóides sobre coelhos diabéticos que, por seu próprio metabolismo, têm maior concentração de triacialgliceróis pela influência da ausência de insulina. O efeito modesto de flavonóides em relação à redução da hipertrigliceridemia, no presente trabalho, pode ser devido ao nível de severidade do estado diabético dos animais. Os hormônios da tireóide podem também influenciar o processo. Segundo Khorle et al., 1985 ${ }^{(31)}$ os flavonóides podem inibir a enzima 5'deiodinase, que catalisa a bioativação de hormônio da tireóide T4 em T3, que é a forma mais ativa. Essa ação é extremamente importante, pois a síntese aumentada do hormônio da tireóide (T3) poderia aumentar a concentração do AMP cíclico. Esse atua, por sua vez, como modulador positivo sobre a quinase da proteína, que ativa a lipase e hidrolisa os triacilgliceróis. Como a enzima que produz a forma mais ativa do hormônio da tireóide é inibida, os efeitos não ocorrem, portanto a atividade da lípase é menor, hidrolisando menos triacilgliceróis, o que acarreta maior concentração deles.

Pesquisadores também demonstraram que flavonóides participam das etapas iniciais da ação de insulina no fígado e músculo de ratos in vivo, efeito que se relaciona com metabolismo lipídico, visto que alguns hormônios específicos atuam em sincronia e sintonia com as células, interferindo sobre a síntese de enzimas, ativação de lipase, inibição de lipoxigenase, ciclooxigenase e especificidade de enzimas ${ }^{(28)}$.

Levando-se em consideração que o aloxano destrói as células $\beta$ do pâncreas, que produzem a insulina, vários efeitos podem ser desencadeados a partir daí. O transporte de glicose ao interior das células depende da presença de insulina anexa aos locais receptores nas membranas das células. Na deficiência de insulina, à glicose não pode atravessar a membrana da célula, acumulando-se no sangue, levando à hiperglicemia e a glicosúria. Exceções são o cérebro, fígado, cristalinos dos olhos, hemácias e a medula renal, nos quais a glicose está apta a difundir-se através da membrana da célula sem a intervenção da insulina ${ }^{(3)}$. 
Tabela II: Concentração média de triacilgliceróis, $(\mathrm{mg} / \mathrm{dL}), \pm$ êrro padrão em soro sanguíneo de coelhos diabéticos, submetidos ao tratamento com antocianina e própolis.

\begin{tabular}{|c|c|c|c|c|c|}
\hline \multirow[t]{2}{*}{ Grupos } & \multicolumn{5}{|c|}{ Dias } \\
\hline & 0 & 7 & 14 & 21 & 28 \\
\hline 1 & $56,80 \pm 2,23$ B & $68,82 \pm 2,20 \mathrm{~B}$ & $73,02 \pm 2,34 \mathrm{~B}$ & $60,95 \pm 2,30 \mathrm{~B}$ & $53,98 \pm 2,20 \mathrm{~B}$ \\
\hline 2 & $432,60 \pm 3,23 \mathrm{~A}$ & $84,12 \pm 2,30 \mathrm{~A}$ & $71,48 \pm 2,35 \mathrm{~A}$ & $86,78 \pm 2,34 \mathrm{~A}$ & $113,70 \pm 3,21 \mathrm{~A}$ \\
\hline 3 & $564,83 \pm 4,40 \mathrm{Ba}$ & $112,14 \pm 2,30 \mathrm{Ba}$ & $96,36 \pm 2,10 \mathrm{Cc}$ & $98,95 \pm 2,34 \mathrm{bC}$ & $87,84 \pm 3,50 \mathrm{aC}$ \\
\hline 4 & $721,08 \pm 2,32 \mathrm{aA}$ & $171,64 \pm 2,32 \mathrm{aB}$ & $112,05 \pm 2,25 \mathrm{aC}$ & $134,60 \pm 4,30 \mathrm{aC}$ & $88,00 \pm 4,20 \mathrm{Ad}$ \\
\hline
\end{tabular}

Concluiu-se que a glicemia nos animais que receberam ração + aloxano + antocianina é diferente daquela dos animais que receberam ração + aloxano + própolis, em cada tempo. A variação ocorrida na glicemia e nos níveis de triacilgliceróis nos animais tratados com ração + aloxano + antocianina ou própolis, em relação ao controle (ração + aloxano) foi estatisticamente significativa, em cada tempo. No entanto, o tratamento com antocianina foi mais eficaz, apresentando maiores reduções dos dois parâmetros. A menor estimativa, no tratamento, foi $72,4 \mathrm{mg} / \mathrm{dL}$, obtida aos 17,4 dias. Isso significa que, até 17,4 dias, a glicose dos animais submetidos a tal tratamento decresceu, atingindo $72,4 \mathrm{mg} / \mathrm{dL}$. No futuro, tais biofármacos poderão ser utilizados como agentes hipoglicêmicos, sendo necessários, ainda, os estudos toxicológicos.

\section{AGRADECIMENTOS}

Os autores agradecem à FAPEMIG e ao $\mathrm{CNPq}$ pelas bolsas concedidas e pelo apoio financeiro.

OLIVEIRA TT; NAGEM TJ; PINTO AS; MESSAGE D; TINOCO ALA; MAGALHÃES NM; SILVA JF; HUERTAS AAG; PINTO JG; PEZERICO GB \& TSIOMIS AC. Effects of anthocyanin and propolis in diabetic rabbits. Medicina, Ribeirão Preto, 35: 464-469, oct./dec. 2002.

ABSTRACT: The diabetes syndrome is characterized by a reduction of the capacity of carbohydrates metabolism and fats, resulting in increase of glucose seric and lipids levels, what can cart in premature vascular degeneration. The experimental groups studied with rabbits were: Group 1 - group controls that only received ration, Group 2 - diabetic group that only received ration, Group 3 - diabetic group that received ration and 1 anthocyanin capsule (20mg) daily; Group 4 diabetic group that received ration and 1 propolis capsule $(150 \mathrm{mg})$ daily. The groups 3 and 4 were submitted to 28 days of treatment, with weekly evaluation of the blood levels of glucose and triacylglicerol. The results showed that during the whole experimental period the anthocyanin were more effective in to reduction of the glucose levels with reductions of $10,78 \%$ to the 7 days, $10,54 \%$ to the 14 days, $17,33 \%$ at the 21 days and $28,09 \%$ to the 28 days. The propolis presented reductions of $1.06 \%$ to the 7 days, $1,10 \%$ to the 14 days, $0,66 \%$ at the 21 days and $22,69 \%$ to the 28 days. The reduction of the percentage of triacylglicerol variation was observed in $22,74 \%$ by the anthocyanin and $22,60 \%$ by the treatment with propolis to the 28 days. In groups 3 and 4 during the whole experimental period, the triacylglicerol levels increased in the period of 7 to the 21 days.

Uniterms: Propolis. Diabetes. Anthocyanin. Triacylglicerol. 


\section{REFERÊNCIAS BIBLIOGRÁFICAS}

1 - ARDUINO F. Diabetes mellitus. $3^{\text {a }}$ ed., Guanabara Koogan, Rio de Janeiro, 1980.

2 - BARRANCO JG. Normas para el control de la glucosa: conceptos actuales. Lect Nutr 54: 14-31,1998.

3 - MAHAN LK \& ARLIN MT. Alimentos, nutrição e dietoterapia. $8^{a}$ ed. Editora Roca, São Paulo, 1995.

4 - BABU PS \& SRINIVASAN K. Influence of dietary curcumin and cholesterol on the progression of experimentally induced diabetes in albino rat. Mol Cell Biochem 152:13-21, 1995.

5 - MORRISON EY. Toxicity of the hyperglycaemic-inducing extract of the annatto (Bixa orellana) in the dog. West $\mathbf{J}$ Med 36: 99-102, 1987.

6 - METZNER J; BEKEMEIER M; PAINTZM \& SCHNEIDWIND E. On the antimicrobial activity of propolis and propolis constituents. Pharmazie 34: 97-102, 1979.

7 - SCHELLER S; KROL W; SWIACKI J; OWCZAREK S; GABRY $\mathrm{J} \&$ SHANI, J. Antitumoral property of ethanolic extract of propolis in mice bearing Erlich carcinoma as compared to becomycin. Z Naturforsch 44: 1063-1065, 1989.

8 - SCHELLER S; WILCZOK T; IMIELSKI S; KROL W; GABRY J \& SHANI J. Free radical scavenging by ethanol extract of propolis. Int J Radiat Biol 57: 461-465, 1990.

9 - WANG L; MINESCHITA SGA; SHIGEMATSU T \& MATSUNO T. Antiinflamatory effect of propolis. J Pharmacol Exp Ther 24: 223-224, 1993.

10 - AMOROS M; SAUVAGER F; GIRRE L \& CORNIER M. In vitro antiviral activity of propolis. Apidologie 23:231-240,1992.

11 - MARCUCCI MC. Propolis: chemical composition, biological properties and therapeutic activity. Apidologie 26: 83-99, 1995.

12 - YAMAMOTO H; UCHIGATA Y \& OKAMOTO H. DNA strand breaks in pancreatic islets by "in vivo" administration of alloxan or streptozotocin. Biochem Biophys Res Comm 103: 1013-1020, 1981

13 - OKAMOTO H. Regulation of proinsulin síntesis in pancreatic islets and new aspects to insulin-dependent diabetes. Moll Cell Biochem 37: 43-61, 1981.

14 - YAMAMOTO H; UCHIGATA Y \& OKAMOTO H. Streptozotocin and alloxan induce DNA strands breaks an poly (ADP-ribose) synthetase in pancreatic islets. Nature 294: 284286, 1981.

15 - UCHIGATA Y; YAMAMOTO H; NAGAI N \& OKAMOTO H. Effect of poly(ADP-ribose) synthetase inhibitor administration to rats before and after injection of alloxan and streptozocin on islet proinsulin synthesis. Diabetes 32: 316$318,1983$.

16 - SCHEIN PS \& LOFTUS S. Streptozocin: depression of mouse liver pyridine nucleotides. Cancer Res 28: 1501-1506, 1968.

17 - HO CK \& HASHIM SA. Pyridine nucleotide depletion in pancreatic islets associated with streptozocin- induced diabetes. Diabetes 21:789-793, 1972.

18 - LAZARUS SS \& SHAPIRO SH. Influence of nicotinamide and puridine nucleotides on streptozocin and alloxan-induced B-cell toxicity. Diabetes 24: 499-506, 1973.
19 - AKPAN JH; WRIGHT PH \& DULIN WE. Effect of diabetogenic nitrosourea on the activity of the pentose phosphate shunt in isolated islets. Acta Diabetol Latinoam 19: 37-47, 1942.

20 - SANDLER S; WELSH M \& ANDERSON A. Streptozotocin induced impairment of islet B-cell metabolism and its prevention by a hydroxyl radical scavanger and inhibitors of poly (ADP-ribose) synthetase. Acta Pharmacol Toxicol 53: 392-400, 1983.

21 - MATUSHIGE K; BASNET P; HASE K; KADOTA S; TANAKA K \& NAMBA T. Propolis protects pancreatic $\beta$-cells against the toxicity of streptozotocin (STZ). Phytomedicine 3: 203209, 1996.

22 - CHRISTINE E L; WALKER, J. R. L; LANCASTER, JE. Effect of polysaccharides on the colour of anthocyanins. Food Chem 54: 315-319, 1995.

23 - GREENWAY W; MAY J; SCAYSBROOK T \& WHATLEY FR. Identification by gas chromatography mass spectrometry of 150 compounds in propolis. Z Naturforsch 46: 11-121, 1991.

24 - DEY PM \& HARBORNE JB. Anthocyanins. Methods Plant Biochem 1: 325-356, 1989.

25 - YOUDIM KA; MCDONALD, J; KALT, J \& JOSEPH, JA. Potential role dietary flavonoids in reducing microvascular endothelium vulnerability to oxidative and inflammatory insults. $\mathbf{J}$ Nutr Biochem 13: 282-288, 2002.

26 - TILTON RG; DAUGHERTY A; SUTERA SP; KENNETHBL; LAND MP; RATERI DL; KILO C \& WILLIAMSON JR Myocyte contracture, vascular resistance, and vascular permeability after global ischemia in isolated hearts from alloxan-induced diabetic rabbits. Diabetes 38:1484-1491, 1989.

27 - THE EXPERT COMMITTEE ON THE DIAGNOSIS AND CLASSIFICATION OF DIABETES MELLITUS. Diabetes Care 23: S4-S19, 2000. Suppl. 1.

28 - CHEEKE PR Alimentación y nutrición del conejo. Academic Press, Isla de Mallorca España 1987.

29 - AGULLO G; GAMET-PAYRASTRE L; MANETI S; VIALA C; RÉMÉSY C; CHAP H \& PAYRASTRE B. Relationship between flavonoids structure and inhibition of phosphatidylinositol3-Kinase: A comparisson with tyrosine kinase and protein kinase on inhibition. Biochem Pharmacol 53:1649-1657, 1997.

30 - GOMES SM. Efeitos de flavonóides no metabolismo lipídico. Dissertação de Mestrado, Centro de Ciências Biológicas e da Saúde da Universidade Federal de Viçosa, Viçosa, p.1-95, 1998.

31 - KHORLE EJ; AUF'MKOLK M; SPANKA M; SONYL G \& HESCH RD. Flavonoids inhibit enzymic thyreoid hormone deiodination. In: FARKAS L; GABOR M \& KALLAY F, eds Flavonoids and bioflavonoids, Academic Science Budapest, Hungarian, p. 411-421, 1985.

Recebido para publicação em 01/12/2000

Aprovado para publicação em 27/12/2002 